\section{CONTRIBUIÇĀO AO ESTUDO DOS ELEMENTOS VASCULARES, ARTERIAIS E VENOSOS, DO HILO RENAL EM CĀES DA RAÇA PASTOR ALEMĀO}

\author{
ROSANO ELIAS RANDI \\ Professor Assistente \\ Faculdade de Medicina Veterinária e \\ Zootecnia da USP \\ ANTONIO FERNANDES FILHO \\ Professor Adjunto \\ Faculdade de Medicina Veterinária e \\ Zootecnia da USP
}

RANDI, R.E. \& FERNANDES FILHO, A. Contribuiçāo ao estudo dos elementos vasculares, arteriais e venosos, do hilo renal em cāes da raça Pastor Alemão. Rev.Fac.Med.vet.Zootec.Univ.S. Paulo, 22(2): 77-95, 1985.

RESUMO: Procurou-se analisar na região hilar o número, a disposição e os locais de entrada e saida, respectivamente dos ramos arteriais e raizes venosas em 30 pares de rins de cães da raça Pastor Alemão, 15 machos e 15 fêmeas, objetivando, nāo apenas melhor conhecer a morfologia destes animais, como também fornecer dados para a Anatomia Comparativa. Os referidos órgāos foram dissecados depois de fixados em solução aquosa de formol a $10 \%$, durante no mínimo 48 horas. Examinados os dados obtidos para o rim direito, relativamente aos ramos arteriais, computados de 7 a 14, verificou-se que o maior povoamento vascular corresponde aos quadrantes craniodorsal e cranioventral. Para as raízes venosas, anotadas de 3 a 5 , a maior concentraçāo foi registrada nos quadrantes cranioventral e caudoventral. No concernente à situação global dos ramos arteriais e raízes venosas, encontrou-se a maioria dos vasos em situação exclusivamente periférica. No rim esquerdo, quanto aos ramos arteriais que variam de 8 a 15, observou-se maior povoamento vascular no quadrante craniodorsal. No tocante às raízes venosas, contadas de 2 a 4 , viu-se maior concentração no quadrante caudoventral. Tanto para os ramos arteriais como para as raizes venosas encontrou-se, па quase totalidade das peças, disposiçāo exclusivamente periférica.

UNITERMOS: Anatomia, cāes $^{+}$; Artérias ${ }^{+}$; Veias ${ }^{+}$; Rins ${ }^{+}$

\section{INTRODUÇĀO}

As inúmeras pesquisas realizadas com o propósito de verificar a disposição dos elementos vasculares renais em animais domésticos, bem como em silvestres, desenvolvidas pelos docentes do Departamento de Cirurgia e Obstetricia da Faculdade de Medicina Veterinária e Zootecnia da Universidade de São. Paulo, principalmente por aqueles que militam na área de Anatomia Descritiva e Topográfica têm, de maneira decisiva, permitido o melhor conhecimento de vários e diferentes aspectos desta importante região anatômica.

Agora, dando continuidade aos aludidos estudos, procuramos analisar o número, a disposição e as regiões de entrada e saida, respectivamente, dos ramos arteriais e raízes venosas dos rins de cães da raça Pastor Alemão, com a finalidade de obter conhecimentos sobre as referidas estruturas nesta espécie, a fím de contribuir para o desenvolvimento da Anatomia Comparada, fornecer subsídios para os trabalhos de natureza cirúrgica, particularmente os de cunho experimental e ainda, caracterizar possiveis aspectos anatômicos, próprios da citada raça.

\section{LITERATURA}

REIS \& TEPE ${ }^{19}$ (1956) e COLLIN ${ }^{5}$ (1972), examinando as estruturas vasculares renais em cães, observaram que a $\mathrm{A}$. renal dividia-se em 2 ramos, antes de penetrar no hilo e a veia mostrava-se por 2 raízes.

ARNAUTOVIC ${ }^{l}$ (1959), estudando o comportamento da artéria renal em 60 cães, assinalou que na quase totalidade dos casos, este vaso bifurcava-se antes de passar pelo hilo.

FULLER \& HUELKE ${ }^{10}(1973)$, à custa de injeções da artéria e veia renais, em 46 cães, com acetato de vinil e posterior corrosão em solução de hidróxido de potássio a $4,0 \%$, registraram a presença de 4 ramos arteriais junto ao hilo, enquanto a veia renal apresentava 2 raizes.

FERRAZ et alii ${ }^{9}$ (1974), analisando os elementos vasculares renais em 14 cães sem raça definida, graças à dissecção, após fixaçāo dos referidos órgãos em solução aquosa de formol a 10,0\%, encontraram, no hilo, a A. renal direita representada por 5 a 12 ramos, enquanto a esquerda por 6 a 12. No tocante à veia renal, esta exibia 1 a 4 raízes, à direita e 2 a 5 , ̀̀ esquerda.

Considerando os compêndios consagrados de Anatomia Veterinária, a maioria dos tratadistas toma por modelo em suas descriçōes os equinos, apresentando para os demais animais domésticos, apenas as diferenças dignas de nota. Desse modo, BOSSI et alii ${ }^{2}$ (s.d.), MONGIARDINO ${ }^{16}$ (1903), MARTIN ${ }^{14}$ (1904), LESBRE ${ }^{13}$ (1923), BRUNI \& ZMMMERL $^{4}$ (1947), SISSON \& GROSSMAN ${ }^{21}$ (i959)。 $\mathrm{KOCH}^{12}$ (1963) afirmam que a A. renal divide-se em vários ramos junto ao hilo, enquanto outros AA. como 
ELLENBERGER \& BAUM $^{7}$ (1894), ZIMMERL et alii22 (1930) e NICKEL et aliil ${ }^{18}$ (1973) encontram esta artéria na regiao hilar, em número de 2 a $5 ; 2$ ou 3 e 2 ramos, respectivamente ou, simplesmente, GONZALES Y GARCLA \& GONZALES ALVAREZ11 (1961), DOBBERSTEIN \& HOFFMANN $^{6}(1963)$ e SCHWARZE \& SCHRÖDER 20 (1970) as mencionam penetrando no hilo sem sofrer divisฮ̃o.

Por outro lado, os tratados dedicados unicamente à anatomia do cao, tais sejam, BRADLEY ${ }^{3}$ (1948), MILLER $^{15}$ (1952) e EVANS \& CHRISTENSEN ${ }^{8}$ (1979), registram obedecendo à ordem, a presença da $\mathrm{A}$. renal em número de 1,2 e 2 novamente, na regiāo hilar, enquanto que MONTANÉ et alii 17 (1953), ao tratarem da anatomia do cão e gato, relatam a divisāo da $A$. renal em 3 ou 4 ramos, antes dela atingir o aludido hilo.

Por fim, no respeitante à veia renal, apenas alguns tratados informam sobre o comportamento deste vaso junto ao hilo. Assim, LESBRE ${ }^{13}$ (1923), GONZALEZ Y GARCIA \& GONZALEZ ALVAREZ ${ }^{11}$ (1961) e $\mathrm{KOCH}^{12}$ (1963) dizem que tal vaso se mostra formado pela convergência de várias raízes, enquanto BOSSI et alii ${ }^{2}$ (s.d) e ZIMMERL et alii 22 (1930) assinalam a presença de 4 ou 5 e 5 ou 6 raízes, e EVANS \& CHRISTENSEN ${ }^{8}$ (1979) descrevem a veia renal representada por 2 raizes na citada região.

\section{MATERIAL E MÉTODO}

Para o presente trabalho, utilizamos 30 pares de rins, obtidos de cães da raça Pastor Alemão, 15 machos e 15 fêmeas, procedentes de diversas clínicas da capital do estado de São Paulo.

Os referidos órgãos, retirados convenientemente, da cavidade abdominal, sempre unidos aos tratos da aorta e da veia cava caudal, foram dissecados, depois de fixados em solução aquosa de formol a 10,0\%. Das peças, uma vez preparadas, colhemos desenhos esquemáticos para ulterior análise e documentação.

Para a descrição dos resultados, consideramos a regiāo hilar, demarcando nela, quadrantes, mediante o auxilio de duas linhas imaginárias perpendiculares entre $s i$, traçadas de polo a polo no sentido dorsoventral, cuja intersecção coincidia com o centro do orifício de seç̧ão transversa justa renal do ureter.

Deste modo, obtivemos quadrantes que receberam as seguintes denominações: craniodorsal, cranioventral, caudodorsal e caudoventral, os quais foram tomados como base para o registro do número e locais de entrada e saída, respectivamente, dos ramos arteriais e das raizes venosas, confrrma nresentamos nos esquemas que representam os pares de rins, submetidos a giro de $90^{\circ}$ obedecendo o sertido medioventral.

\section{RESULTADOS}

Baseados no exame das dissecções dos 30 pares de rins, de cães da raça Pastor Alemão, apresentamos os resultados nos QUAD. 1,2,3 e 4, correspondentes ao número, disposição e as regiões de entrada e saída, respectivamente dos ramos arteriais e das raízes venosas, das artérias e veias renais (esquemas de 1 a 30 ), obedecendo na região hilar aos quadrantes e linhas, previamente traçados para os rins direito e esquerdo.

\section{COMENTÁRIOS}

O comportamento dos elementos vasculares renais, quanto ao número, disposiçāo e às regiōes de entrada e saida, respectivamente, dos ramos da artéria renal e raízes da veia renal, obtidos agora em cães da raça Pastor Alemão, permite certo confronto com os dados apresentados pelos pesquisadores que examinaram o assunto, também em cães, bem como, com tratadistas que na maioria das vezes, em suas descrições tomam os equinos por modelo e apresentam para as outras espécies domésticas, somente as diferenças dignas de destaque.

Assim, com relação ao número de ramos das artérias renais, REIS \& TEPE ${ }^{19}$, ARNAUTOVIC ${ }^{1}$ e COLLIN ${ }^{5}$ verificaram nessa espécie a presença de 2 ramos, antes deste vaso atingir o hilo do aludido órgão, fato que muito difere dos nossos resultados, pois encontramos de 7 a 15 ramos, o mesmo acontecendo em relação a FULLER \& HUELKE ${ }^{10}$, que observaram também para os cães a presença de 4 ramos, junto ao mencionado hilo.

Ainda neste particular, FERRAZ et alii ${ }^{9}$, utilizando a mesma metodologia por nós empregada, em cđ̃es sem raça definida, assinalaram na região hilar, de 5 a 12 ramos para o rim direito e de 6 a 12 para o esquerdo, o que se aproximou dos dados agora vistos em Pastores Alemaes, vale dizer, de 7 a 14 à direita e de 8 a 15 d̀ esquerda.

No que tange às raizes venosas, REIS \& TEPE ${ }^{19}$, $\operatorname{COLLIN~}^{5}$ e FULLER \& HUELKE ${ }^{10}$ são unânimes em afirmar que a veia renal se apresenta formada por 2 raízes, na regico hilar, fato observado em nossas peças apenas 2 vezes $(6,7 \%)$, à esquerda, enquanto FERRAZ et alii ${ }^{9}$ anotaram junto ao hilo, de 1 a 4 e de 2 a 5 raízes, respectivamente, para os rins direito e esquerdo, valores estes que muito se aproximam dos nossos, pois vimos de 3 a 5 , à direita, e de 2 a 4 , d esquerda.

No respeitante à situação global dos ramos arteriais na regiđo hilar, não considerada por nenhum dos AA. consultados, verificamos que estes mostram localização exclusiva. mente periférica $(93,3 \%)$ e predominantemente periférica $(6,7 \%)$, para o rim direito, enquanto para o esquerdo estes vasos ocupam posição exclusivamente periférica em todo: os casos. Também no tocante à distribuição das raizes de 
veia renal junto ao hilo, que registramos com situação ex clusivamente periférica $(86,7 \%)$ e predominantemente periférica $(13,3 \%)$, à direita e exclusivamente periférica $(93,3 \%)$ e predominantemente periférica $(6,7 \%)$, à esquerda, disposiçðes nao encontradas por parte dos AA. mencionados.

Com referência ao povoamento dos quadrantes pelos ramos arteriais, devemos destacar maior concentração destes vasos, nos quadrantes craniodorsal e cranioventral, seguindo-se os quadrantes caudodorsal e caudoventral para o rim direito, enquanto para o esquerdo o quadrante craniodorsal mostra a presença de maior número de ramos, seguindo-se os quadrantes cranioventral, caudodorsal e caudoventral.

Já, no pertinente ao povoamento das raizes venosas hilares, devemos ressaltar que sua maior concentração à direita é registrada nos quadrantes cranioventral e caudoventral, seguidos dos quadrantes craniodorsal e caudodorsal e, à esquerda, no quadrante caudoventral, seguindo os quadrantes craniodorsal, cranioventral e caudodorsal.

De outra parte, pudemos evidenciar que, ouleralmente, igual número de ramos arteriais ocorrem 13 vezes $(43,3 \%)$ e, de raizes venosas, 19 vezes $(63,3 \%)$.

Analisando, agora, as informações colhidas nos tratados consagrados à Anatomia Veterinária, nos são permitidas apenas algumas comparações de caráter geral, devido à imprecisão como tratam do assunto. De fato, BOSSI et alii ${ }^{2}$, MONGIARDINO ${ }^{16}$, MARTIN ${ }^{14}$, LESBRE ${ }^{13}$, BRUNI \& ZIMMERL $^{4}$, SISSON \& GROSSMAN ${ }^{21}$ e $\mathrm{KOCH}^{12}$, ao se referirem à artéria renal, apenas comentam que a mesma se divide em vários ramos. Por outro lado, os AA. como ELLENBERGER \& $\mathrm{BAUM}^{7}$, ZLMMERL et alii ${ }^{22}$, NICKEL et alii 18 , que citam a artéria renal dividindo-se em 2 a $5 ; 2$ ou 3 e 2 ramos, respectivamente, muito se distanciam dos nossos achados, pois os cães Pastores Alemaes apresentam de 7 a 14 ramos à direita e de 8 a 15 à esquerda.

Já, relativamente à afirmação de GONZALEZ Y GARCLA \& GONZALEZ ALVAREZ ${ }^{11}$, DOBBERSTEIN \& HOFFMAN $^{6}$ e SCHWARZE \& SCHROODER 20 em seus compendios, que a A. renal mostra-se indivisa junto ao hilo, devemos lembrar que tal disposiçāo nāo registramos na raça ora estudada.

Mesmo aqueles AA. que se preocupam exclusivamente com o cão, tais como BRADLEY ${ }^{3}$, MILLER $^{15}$, MONTANE et alii 17 , EVANS \& CHRISTENSEN ${ }^{8}$ e que afirmam, por ordem, possuir a $A$. renal $1,2,3$ ou 4 e 2 ramos, assinalaram valores também ausentes nas nossas preparaçð̄es.

Por fim, ao confrontarmos os valores relativos ao número de ramos arteriais e raízes venosas dos rins direito e esquerdo, não encontromns diferenças estatisticamente significativas, relauvamente ao sexo, ao nivel de rejeição de $5,0 \%$.

\section{CONCLUSŌES}

A análise dos resultados obtidos em 30 pares de rins de cães de raça Pastor Alemão, com objetivo de observar o número, disposição e os locais de entrada e saída, respectivamente, dos ramos arteriais e raízes venosas na regiāo hilar, possibilitou-nos chegar às seguintes conclusões:

1) os ramos arteriais dispostos nessa região são identificados, no rím direito, em número de onze $(30,0 \%)$, nove $(23,3 \%)$, dez $(20,0 \%)$, três $(10,0 \%)$, doze $(6,7 \%)$, quatorze $(3,3 \%)$, oito $(3,3 \%)$ e sete $(3,3 \%)$ e, no esquerdo, em número de onze $(26,7 \%)$, treze $(23,3 \%)$, dez $(13,3 \%)$, nove $(13,3 \%)$, quatorze $(6,7 \%)$, doze $(6,7 \%)$, oito $(6,7 \%)$ e quinze $(3,3 \%)$;

2) as raizes venosas são encontradas, no rim direito, em número de quatro $(60,0 \%)$, três $(30,0 \%)$ e cinco $(10,0 \%)$ e, no esquerdo, em número de quatro $(56,7 \%)$, três $(36,7 \%)$ e duas $(6,7 \%)$;

3) os ramos arteriais no rim direito localizam-se em situação exclusivamente periférica -28 vezes $(93,3 \%)$ e predominantemente periférica -2 vezes $(6,7 \%)$, enquanto no rim esquerdo acham-se sempre em posição exclusivamente periférica;

4) as raízes venosas do rim direito encontram-se com situação exclusivamente periférica -26 vezes $(86,7 \%)$ e predominantemente periférica -4 vezes $(13,3 \%)$, enquanto que no rim esquerdo acham-se em posição exclusivamente periférica - 28 vezes $(93,3 \%)$ e predominantemente periférica -2 vezes $(6,7 \%)$;

5) nos 30 pares de rins dissecados verificamos, para os rins direito e esquerdo, igual número de ramos arteriais -13 vezes $(43,3 \%)$ e de raizes venosas -19 vezes $(63,3 \%)$, coincidindo somente 9 vezes $(30,0 \%)$ o número total de ramos arteriais e raízes venosas à direita e esquerda;

6) nđo foram identificadas diferenças estatisticamente significantes, ao nivel de $5,0 \%$, quando confrontamos o número de ramos arteriais e de raizes venosas encontradas na região hilar de ambos os rins, entre machos e fêmeas.

RANDI, R.E. \& FERNANDES FILHO, A. A contribution to the study of arterial and venous vascularization of the kidney hilus in German Shepherd dogs. Rev.Fac.Med.vet.Zootec.Univ.S. Paulo, 22(2): 77-95, 1985.

SUMMARY: In this paper we studicd the number, distribution, the entry and exit sites of arterial branches and venous roots in 30 pairs of kidneys obtained from 15 male and 15 female German Shepherd dogs. The paper was cione not only to improve our knowledge of the kidney morphology but also to bring some data to 
comparative anatomy. The kidneys were dissected, at least 48 hours, after being fixed in a $10 \%$ formalin solution. Concerning the right kidney the arterial branches numbered 7 to 14 were localized in the craniodorsal and cranioventral quadrants while the venous roots numbered from 3 to 5 predominated in the cranioventral and caudoventral quadrants. Most of the vessels showed peripheral situation. In relation to the left kidney the arterial branches numbered from 8 to 15 were seen in the craniodorsal quadrant and the venous roots numbered 2 to 4 in the caudoventral quadrant. We found an exclusive peripherical situation for the arterial branches and venous roots in almost all kidneys examined.

UNITERMS: Anatomy of $\operatorname{dog}^{+}$; Arteries ${ }^{+}$; Veins ${ }^{+}$; Kidney ${ }^{+}$

QUADRO 1 - Ramos arteriais hilares da artéria renal direita, de cães da raça Pasto _ـ Ne. mão, segundo sua localização. São Paulo, 1984.

\begin{tabular}{|c|c|c|c|c|c|c|}
\hline \multirow{3}{*}{ OBS. } & \multicolumn{5}{|c|}{ Lo c a l i z a ç $\tilde{a} \circ$} & \multirow{3}{*}{ Total } \\
\hline & \multicolumn{4}{|c|}{ QUADRANTES } & \multirow{2}{*}{$\begin{array}{l}\text { Limite dos } \\
\text { Quadrantes }\end{array}$} & \\
\hline & SRV & CRD & CAV & CAD & & \\
\hline $1 \mathrm{~m}$ & 1 & 2 & 2 & 2 & CRV-CAV - 1 CRD-CAD - 1 & 9 \\
\hline $2 \mathrm{~m}$ & 4 & 3 & 2 & 3 & $C R V-C R D-1$ & 13 \\
\hline $3 \mathrm{~m}$ & 3 & 2 & 2 & 2 & - & 9 \\
\hline $4 \mathrm{~m}$ & 3 & 3 & 3 & 2 & - & 11 \\
\hline $5 \mathrm{~m}$ & 3 & 3 & 3 & 3 & - & 12 \\
\hline $6 \mathrm{~m}$ & 2 & 1 & 2 & 2 & - & 7 \\
\hline $7 \mathrm{~m}$ & 2 & 3 & 3 & 2 & - & 10 \\
\hline $8 \mathrm{~m}$ & 3 & 3 & 3 & 2 & - & 11 \\
\hline $9 \mathrm{~m}$ & 4 & 2 & 2 & 3 & - & 11 \\
\hline $10 \mathrm{~m}$ & 2 & 4 & 1 & 2 & CRV - CAV - 1 & 10 \\
\hline $11 \mathrm{in}$ & 3 & 2 & 2 & 2 & - & 9 \\
\hline $12 \mathrm{~m}$ & 4 & 3 & 2 & 3 & - & 12 \\
\hline $13 \mathrm{~m}$ & 4 & 4 & 3 & 2 & - & 13 \\
\hline $14 \mathrm{~m}$ & 3 & 2 & 2 & 2 & - & 9 \\
\hline $15 \mathrm{~m}$ & 3 & 2 & 1 & 2 & $C R D-C A D-1$ & 9 \\
\hline $16 f$ & 2 & 4 & 2 & 2 & - & 10 \\
\hline $17 \mathrm{f}$ & 4 & 3 & 1 & 2 & - & 10 \\
\hline $18 \mathrm{f}$ & 3 & 6 & 2 & 3 & - & 14 \\
\hline $19 \mathrm{f}$ & 3 & 3 & 2 & 2 & - & 10 \\
\hline $20 \mathrm{f}$ & 3 & 3 & 3 & 2 & - & 11 \\
\hline $21 \mathrm{f}$ & 2 & 4 & 3 & 2 & - & 11 \\
\hline $22 \mathrm{f}$ & 4 & 3 & 2 & 2 & - & 11 \\
\hline $23 \mathrm{f}$ & 3 & $j$ & 2 & 3 & - & 11 \\
\hline $24 f$ & 4 & 2 & 3 & 2 & - & 11 \\
\hline $25 \mathrm{f}$ & 4 & 2 & 2 & 3 & - & 11 \\
\hline $26 \mathrm{f}$ & 3 & 3 & 2 & 2 & - & 10 \\
\hline $27 \mathrm{f}$ & 3 & 3 & 1 & 2 & - & 9 \\
\hline $28 \mathrm{f}$ & 3 & 5 & 2 & 3 & - & 13 \\
\hline $29 f$ & 2 & 3 & 2 & 2 & - & 9 \\
\hline $30 \mathrm{f}$ & 1 & 2 & 3 & 2 & - & 8 \\
\hline
\end{tabular}

$$
\begin{aligned}
& \text { CRV - Quadrante cranioventral } \\
& \text { CRD - Quadrante craniodo } \ldots . .4 \\
& \text { m - Macho } \\
& \text { f - Fémea }
\end{aligned}
$$$$
\text { CAV-Quadrante caudoventral }
$$$$
\text { CAD - Quadrante caudodorsal }
$$ 
QUADRO 2 - Raízes hilares da veia renal direita, de cães da raça Pastor Alemão, segundo sua localização. São Paulo, 1984.

\begin{tabular}{|c|c|c|c|c|c|c|}
\hline \multirow{3}{*}{ OBS. } & \multicolumn{5}{|c|}{ Loc a 1 i z a c ào } & \multirow{3}{*}{ Total } \\
\hline & \multicolumn{4}{|c|}{ QUADRANTES } & \multirow{2}{*}{$\begin{array}{l}\text { Limite dos } \\
\text { Quadrantes }\end{array}$} & \\
\hline & CRV & CRD & CAV & $\mathrm{CAD}$ & & \\
\hline $1 \mathrm{~m}$ & - & 1 & 2 & - & - & 3 \\
\hline $2 \mathrm{~m}$ & 1 & - & - & - & CRV-CRD - I CAV-CAD - 1 & 3 \\
\hline $3 \mathrm{~m}$ & 1 & 1 & 1 & 1 & - & 4 \\
\hline $4 \mathrm{~m}$ & 2 & 1 & 1 & - & - & 4 \\
\hline $5 \mathrm{~m}$ & 1 & 1 & 1 & 1 & - & 4 \\
\hline $6 \mathrm{~m}$ & - & 1 & - & 1 & $C R V-C R D-2$ & 4 \\
\hline $7 \mathrm{~m}$ & 1 & 1 & 2 & - & - & 4 \\
\hline $8 \mathrm{~m}$ & 2 & 1 & - & - & $C A V-C A D-1$ & 4 \\
\hline $9 \mathrm{~m}$ & 1 & 1 & 1 & 1 & - & 4 \\
\hline $10 \mathrm{~m}$ & 1 & - & 1 & - & $C A V-C A D-1$ & 3 \\
\hline $11 \mathrm{~m}$ & 1 & 1 & - & 1 & - & 3 \\
\hline $12 \mathrm{~m}$ & 2 & 1 & 1 & 1 & - & 5 \\
\hline $13 \mathrm{~m}$ & 1 & 1 & 1 & 1 & - & 4 \\
\hline $14 \mathrm{~m}$ & 1 & - & - & - & CRV-CRD - I CAV-CAD - 1 & 3 \\
\hline $15 \mathrm{~m}$ & 2 & 1 & 1 & 1 & - & 5 \\
\hline $16 f$ & 1 & 2 & 1 & - & - & 4 \\
\hline $17 \mathrm{f}$ & 1 & 1 & 1 & 1 & - & 4 \\
\hline $18 \mathrm{f}$ & 1 & 1 & 2 & - & - & 4 \\
\hline $19 \mathrm{f}$ & - & 1 & 2 & - & - & 3 \\
\hline $20 f$ & 1 & 1 & 1 & 1 & - & 4 \\
\hline $21 \mathrm{f}$ & 1 & 1 & 2 & - & - & 4 \\
\hline $22 \mathrm{f}$ & 1 & 1 & 1 & 1 & - & 4 \\
\hline $23 f$ & 1 & 1 & 1 & 1 & - & 4 \\
\hline $24 \mathrm{f}$ & 1 & 1 & 1 & - & - & 3 \\
\hline $25 \mathrm{f}$ & 1 & 1 & 1 & 1 & - & 4 \\
\hline $26 \mathrm{f}$ & 1 & 1 & 1 & 1 & - & 4 \\
\hline $27 \mathrm{f}$ & 1 & 1 & 1 & - & - & 3 \\
\hline $28 \mathrm{f}$ & 1 & 1 & 2 & 1 & - & 5 \\
\hline $29 f$ & 1 & 1 & 1 & - & $C A V-C A D-1$ & 4 \\
\hline $30 \mathrm{f}$ & 1 & 1 & 1 & - & - & 3 \\
\hline \multicolumn{5}{|c|}{ CRV - Quadrante cranioventral } & \multicolumn{2}{|l|}{ CAV - Quadrante caudoventral } \\
\hline \multicolumn{5}{|c|}{ CRD - Quadrante craniodorsal } & \multicolumn{2}{|l|}{ CAD - Quadrante caudodorsal } \\
\hline \multicolumn{7}{|c|}{ m - Macho } \\
\hline$f-$ & & & & & & \\
\hline
\end{tabular}

Rev.Fac.Med.vet.Zootec.Univ.S.Paulo, 22(2): 77-95, 1985 
QUADRO 3 - Ramos arteriais hilares da artéria renal esquerda, de cães da raça Pustor Alemão, segundo a localização. São Paulo, 1984.

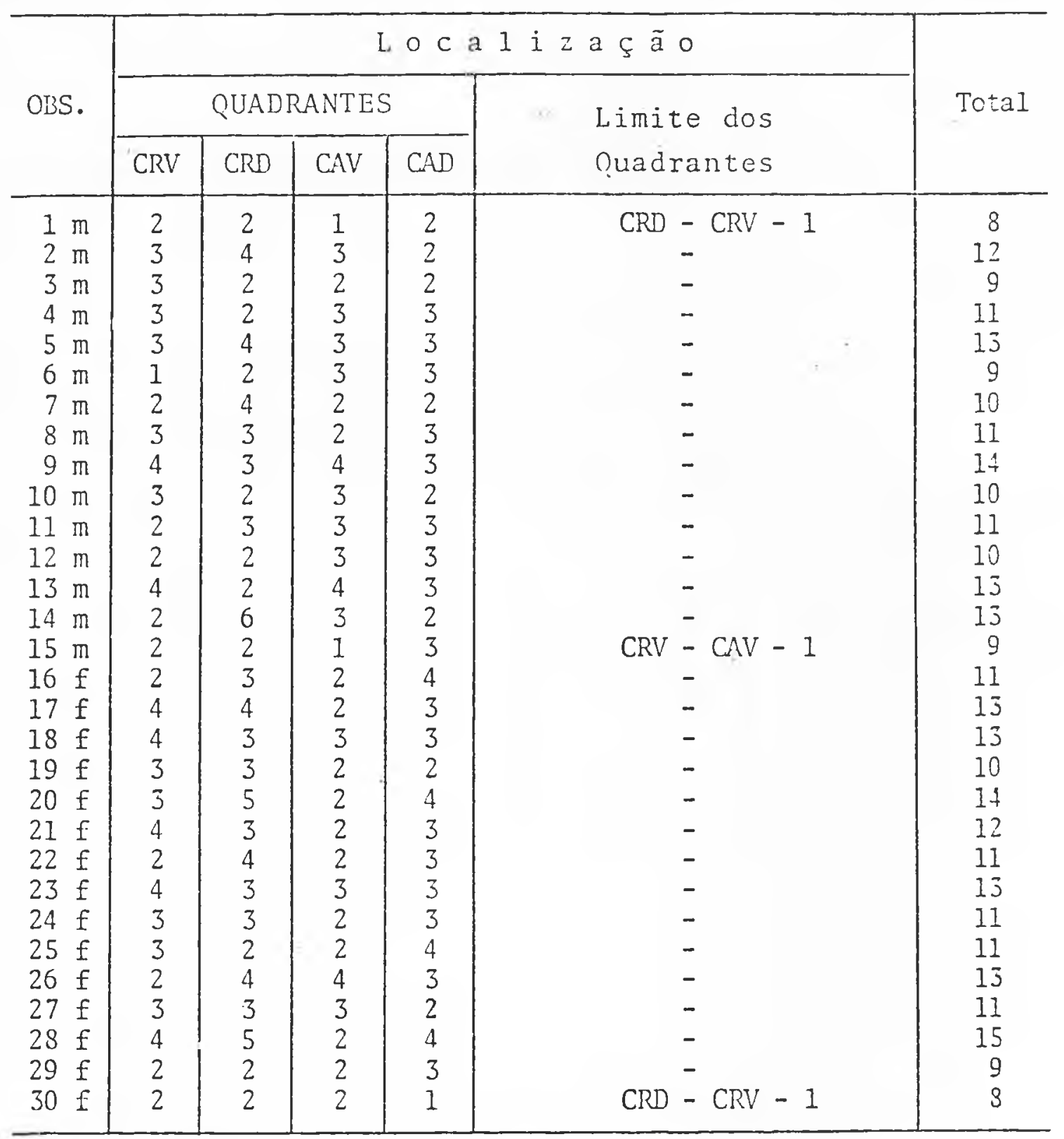

$$
\begin{array}{ll}
\text { CRV - Quadrante cranióventral } & \text { CAV - Quadrante caudoventral } \\
\text { CRD - Quadrante craniodorsal } & \text { CAD - Quadrante caudodorsal } \\
\text { m - Macho } & \\
\text { f - Fêmea } &
\end{array}
$$


QUADRO 4 - Raizes hilares da veia renal esquerda, de cães da raça Pastor Alemão, segundo a localização. São Paulo, 1984.

\begin{tabular}{|c|c|c|c|c|c|c|}
\hline \multirow{3}{*}{ OBS. } & \multicolumn{5}{|c|}{ L $\circ c$ a 1 i $z$ a $c ̧ \tilde{a} \circ$} & \multirow{3}{*}{ Total } \\
\hline & \multicolumn{4}{|c|}{ QUADRANTES } & \multirow{2}{*}{$\begin{array}{l}\text { Limite dos } \\
\text { Quadrantes }\end{array}$} & \\
\hline & CRV & CRD & CAV & $\mathrm{C} A \mathrm{D}$ & & \\
\hline $1 \mathrm{~m}$ & 1 & 1 & 1 & - & - & 3 \\
\hline $2 m$ & 1 & - & - & - & $C R D-C R V-1 C A D-C A V-1$ & 3 \\
\hline $3 \mathrm{~m}$ & 1 & 1 & 1 & 1 & . - & 4 \\
\hline $4 \mathrm{~m}$ & 2 & - & 1 & 1 & - & 4 \\
\hline $5 \mathrm{~m}$ & 1 & 1 & 1 & 1 & - & 4 \\
\hline $6 \mathrm{~m}$ & - & - & 2 & - & $C R D-C R V-1$ & 3 \\
\hline $7 \mathrm{~m}$ & - & 1 & 1 & - & - & 2 \\
\hline $8 \mathrm{~m}$ & 1 & 1 & 2 & - & - & 4 \\
\hline $9 \mathrm{~m}$ & 1 & 1 & 1 & 1 & - & 4 \\
\hline $10 \mathrm{~m}$ & 1 & 1 & 1 & - & - & 3 \\
\hline חנ 11 & 1 & 1 & 1 & - & - & 3 \\
\hline $12 \mathrm{~m}$ & 1 & 1 & 1 & 1 & - & 4 \\
\hline $13 \mathrm{~m}$ & 1 & 1 & 1 & 1 & - & 4 \\
\hline $14 \mathrm{~m}$ & - & 1 & 1 & - & - & 2 \\
\hline 15 ת & 1 & 1 & 1 & - & - & 3 \\
\hline $16 \mathrm{f}$ & 1 & 1 & 1 & 1 & - & 4 \\
\hline $17 \mathrm{f}$ & 1 & 1 & - & 1 & - & 3 \\
\hline $18 \mathrm{f}$ & 1 & 1 & 1 & 1 & - & 4 \\
\hline $19 \mathrm{f}$ & 1 & 1 & 2 & - & - & 4 \\
\hline $20 \mathrm{f}$ & 1 & 1 & 1 & 1 & - & 4 \\
\hline $21 \mathrm{f}$ & 1 & 1 & 1 & 1 & - & 4 \\
\hline $22 \mathrm{f}$ & - & 1 & 2 & - & - & 3 \\
\hline $23 \mathrm{f}$ & 1 & 1 & 1 & - & - & 3 \\
\hline $24 \mathrm{f}$ & 1 & 1 & 1 & - & - & 3 \\
\hline $25 \mathrm{f}$ & 1 & 1 & 1 & 1 & - & 4. \\
\hline $26 \mathrm{f}$ & 1 & 1 & 1 & 1 & - & 4 \\
\hline $27 \mathrm{f}$ & 1 & 1 & 1 & 1 & - & 4 \\
\hline $28 \mathrm{f}$ & 1 & 1 & 1 & 1 & - & 4 \\
\hline $29 \mathrm{f}$ & 1 & 1 & 2 & - & - & 4 \\
\hline 301 & 1 & 1 & 1 & - & - & 3 \\
\hline
\end{tabular}

CRV - Quadrante cranioventral

m - Macho

f - Fêmea 
Representações esquemáticas dos ramos arteriais e das raízes venosas da. região hilar, nos rins direito e esquerdo (E), de cães (Canis familiares), consi-derando os órgãos submetidos a giro de $90^{\circ}$, no sentido medioventral.

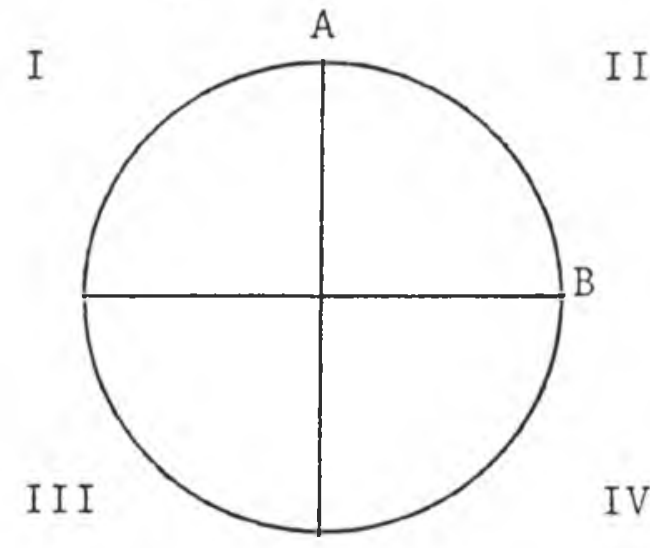

D

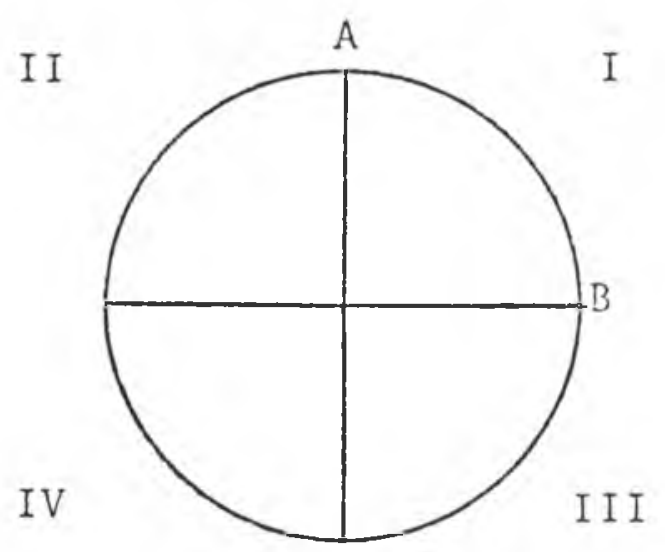

E

$$
\begin{aligned}
& \text { A - linha craniocaudal } \\
& \text { B - linha dorsoventral } \\
& \text { D - hilo renal direito } \\
& \text { E - hilo renal esquerdo } \\
& \text { I - quadrante cranioventral } \\
& \text { II - quadrante craniodorsal } \\
& \text { II - quadrante caudoventral } \\
& \text { IV - quadrante caudodorsal } \\
& \text { - ureter } \\
& \text { - ramo arterial } \\
& \text { - ramo venoso }
\end{aligned}
$$




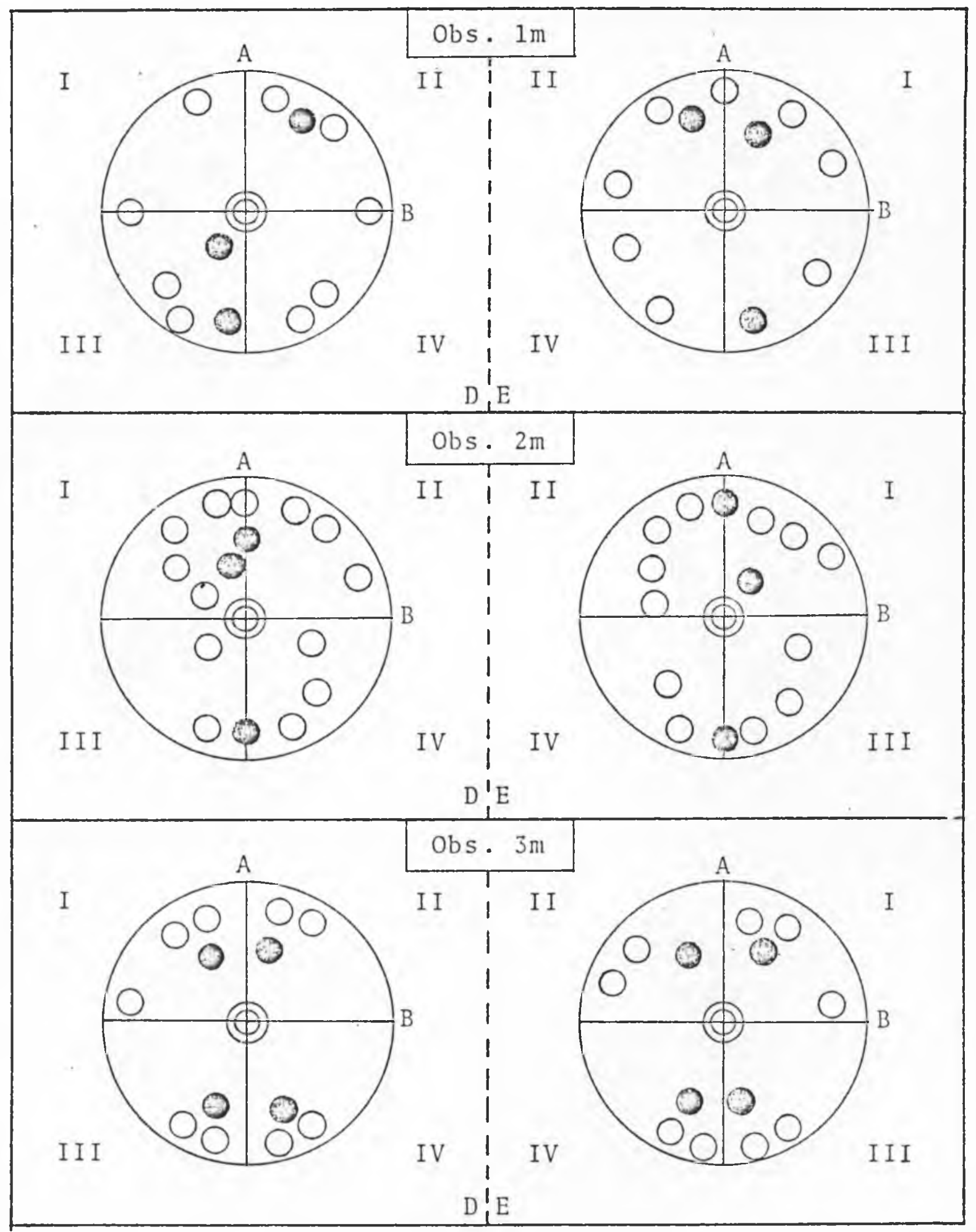

Rev.Fac.Med.vet.Zootec.Univ.S.Paulo, 22(2): 77-95, 1985 


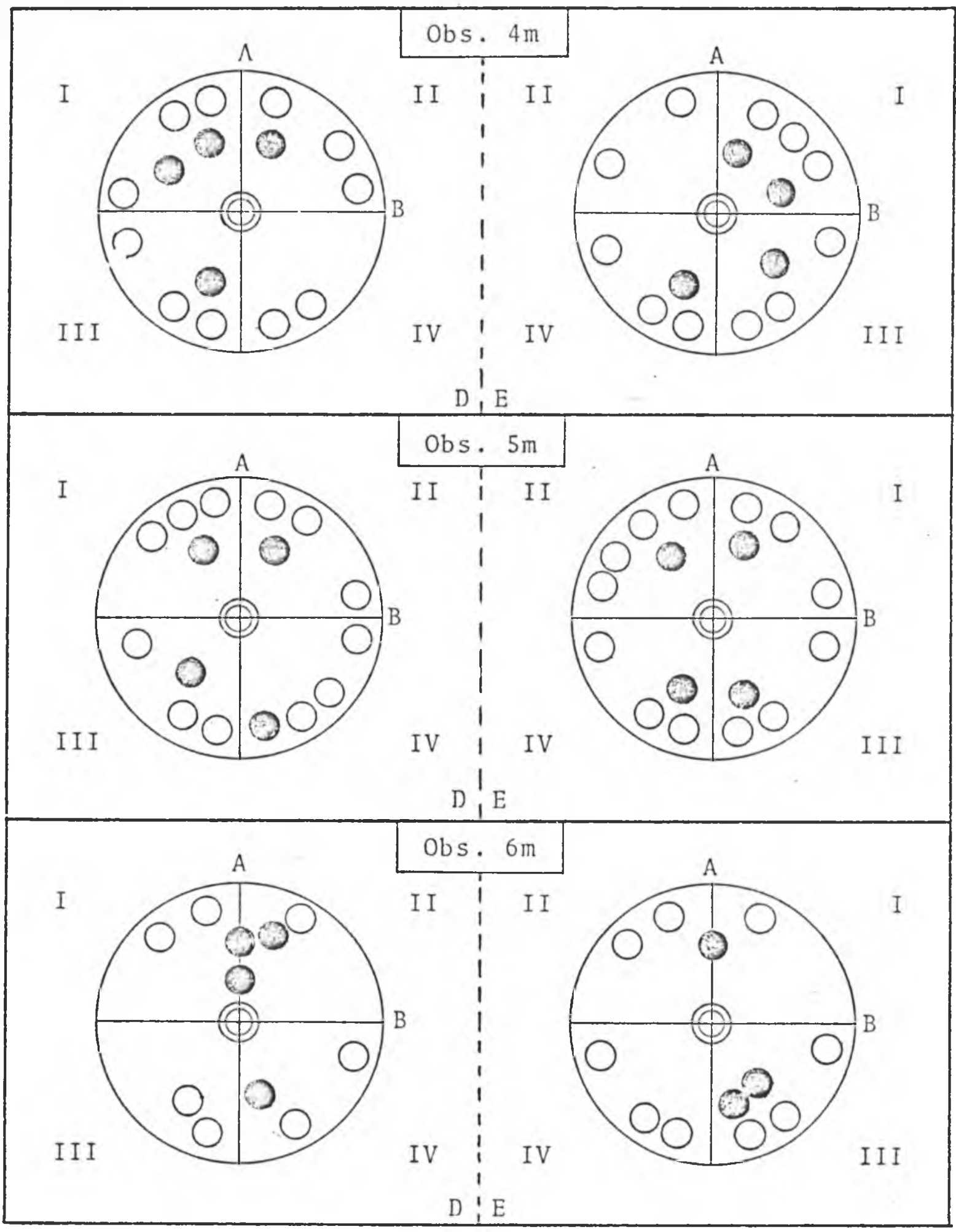




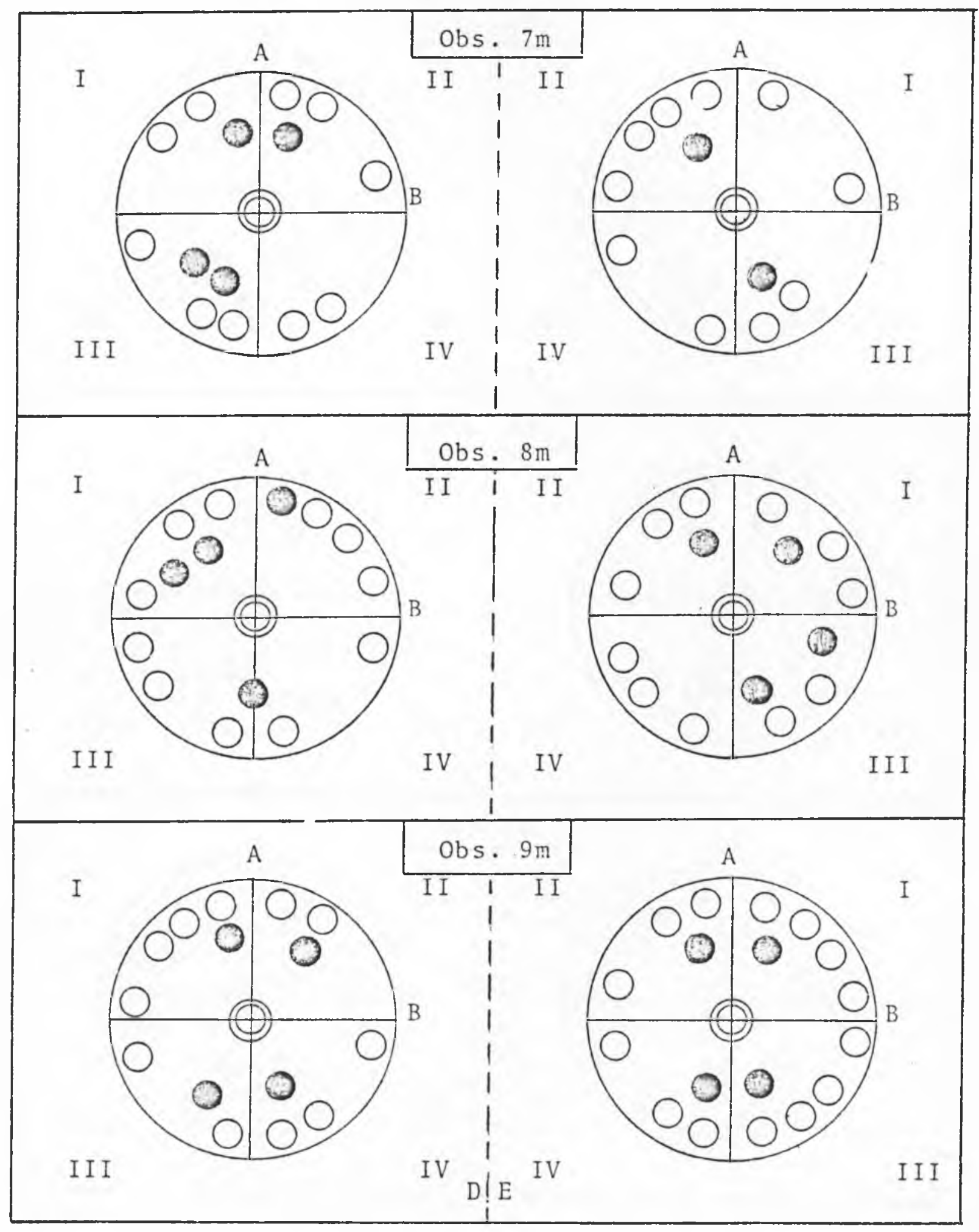

Rev.Fac.Med.vet.Zootec.Univ.S.Paulo, 22(2): 77-95, 1985 


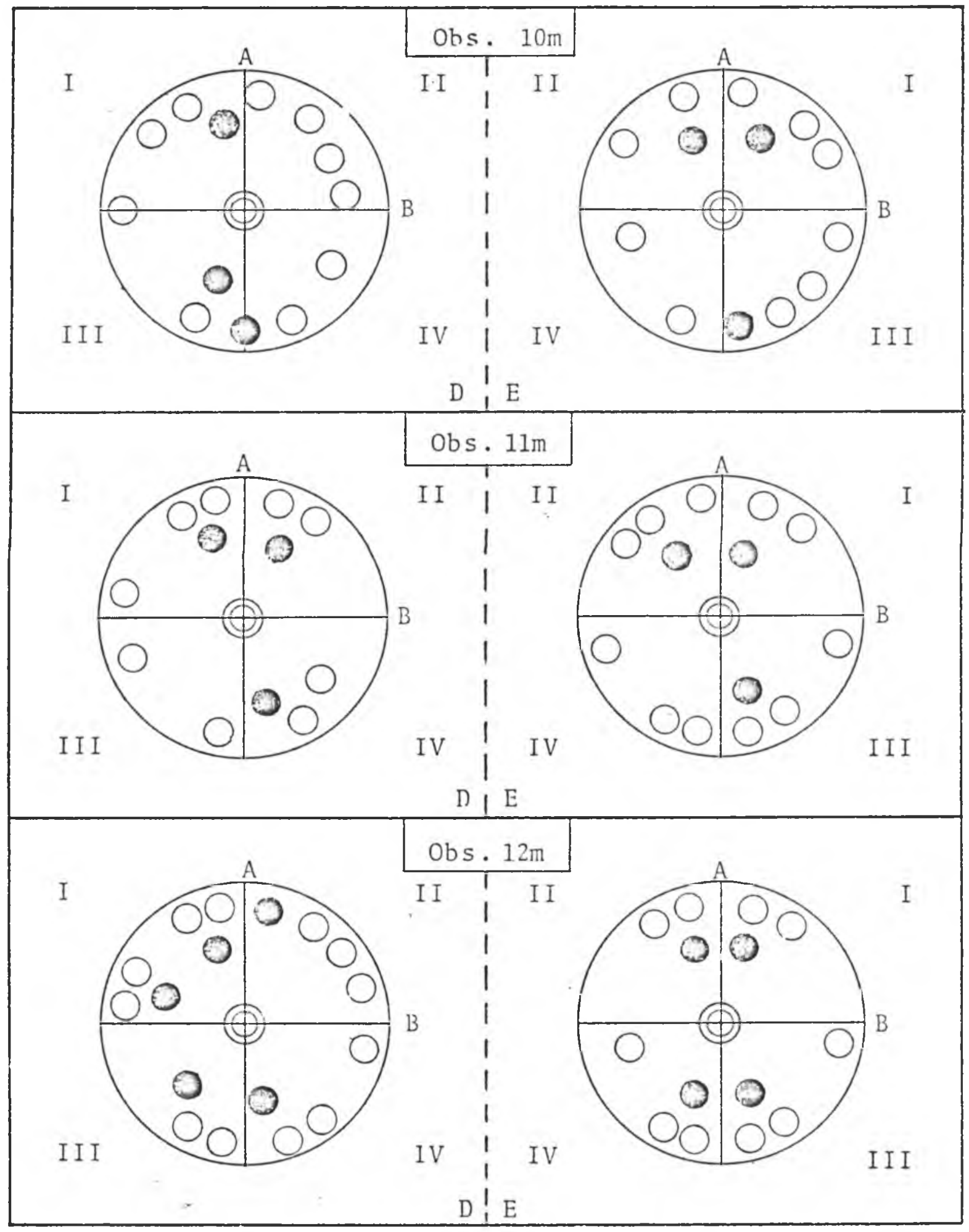




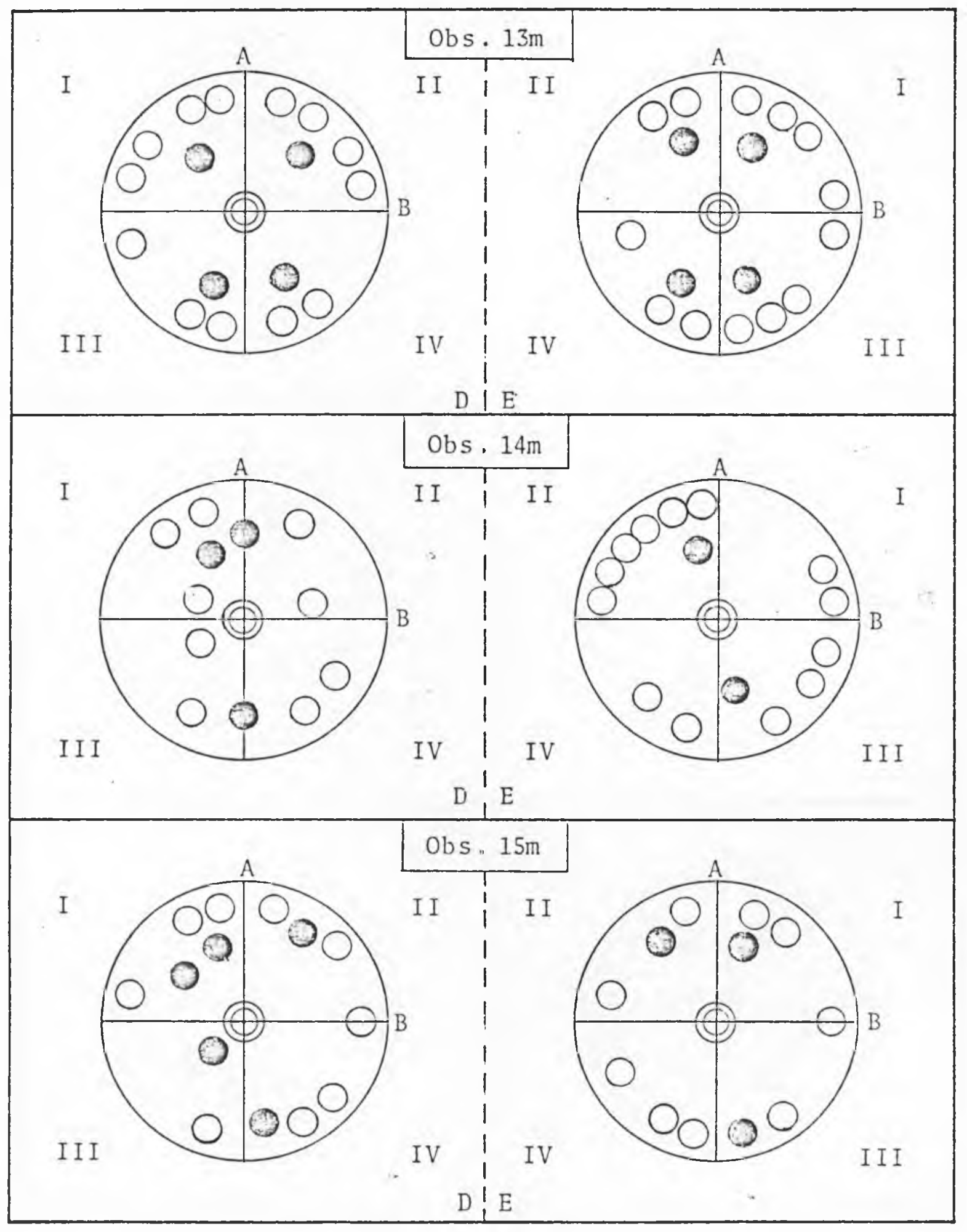

Rev.Fac.Med.vet.Zootec.Univ.S.Paulo, 22(2): 77-95, 1985 


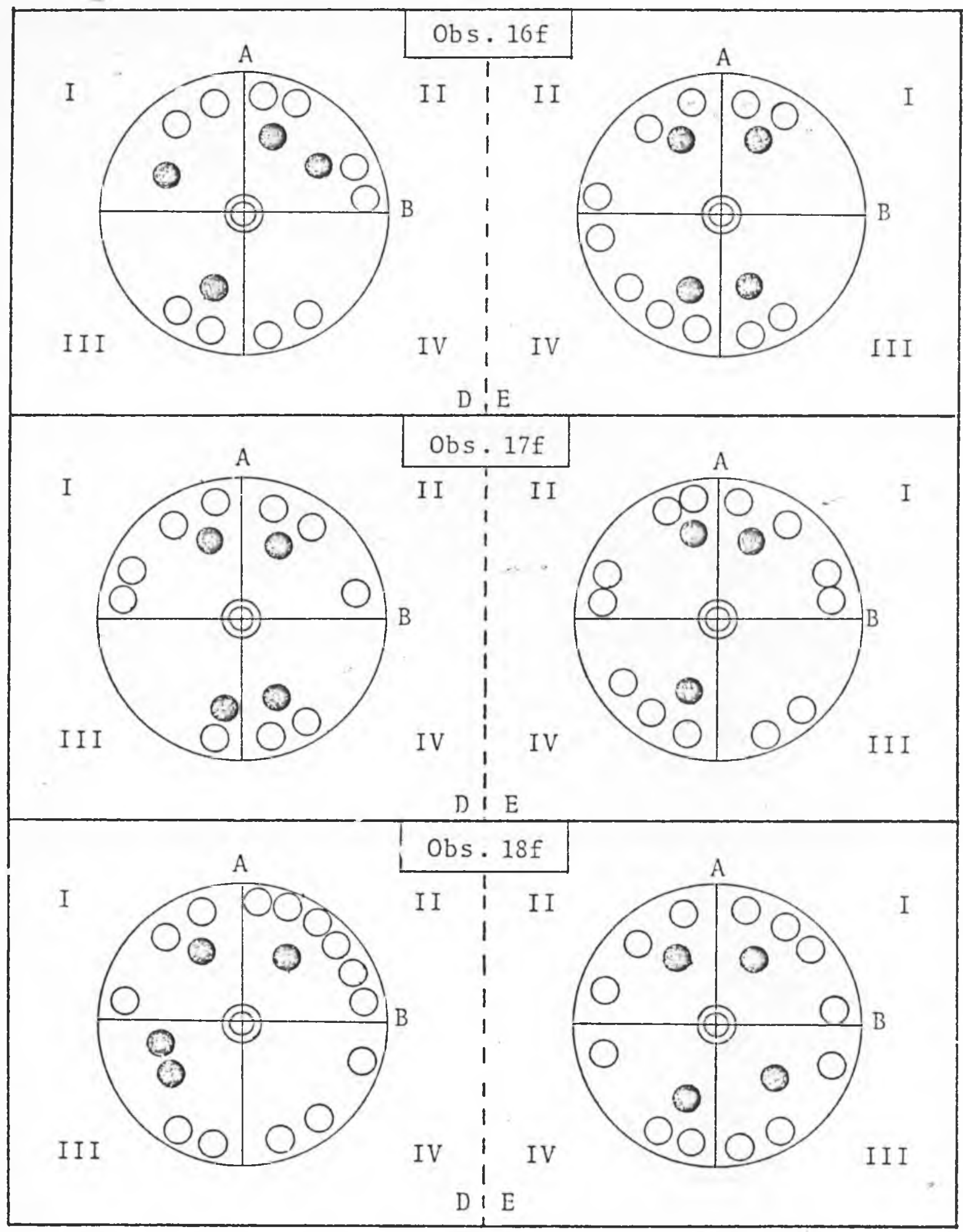




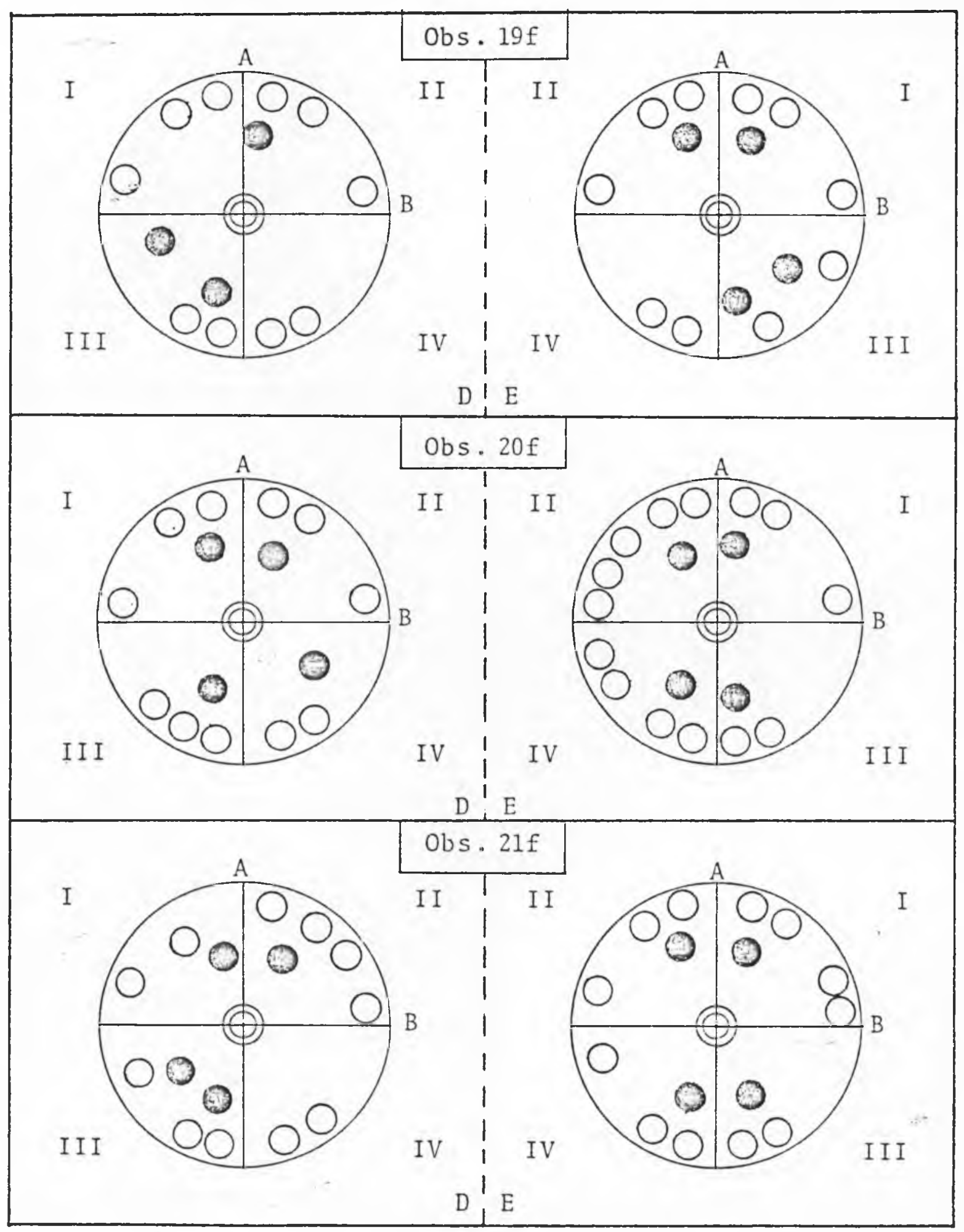

Rev.Fac.Med.vet.Zootec.Univ.S.Paulo, 22(2): 77-95, 1985 


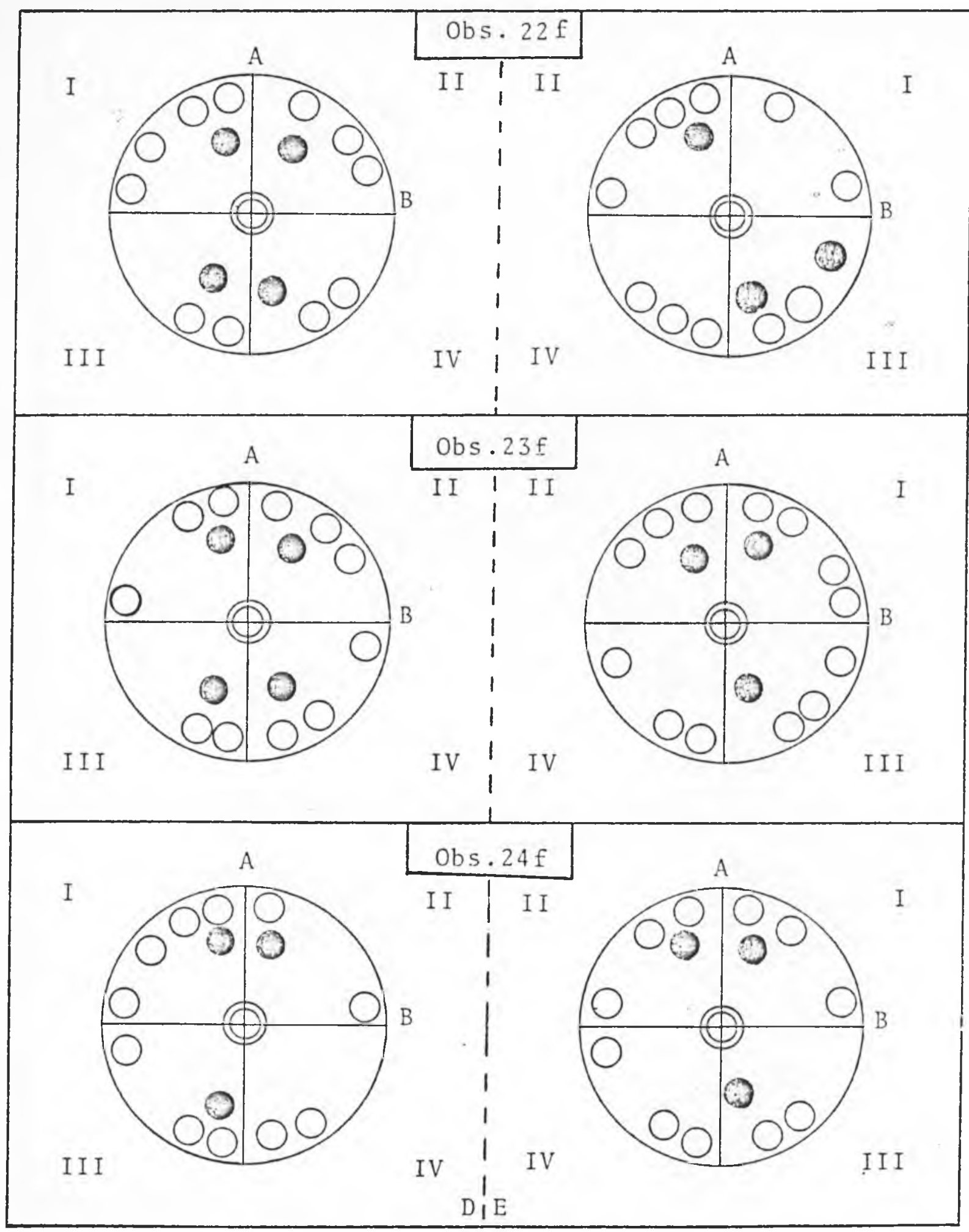




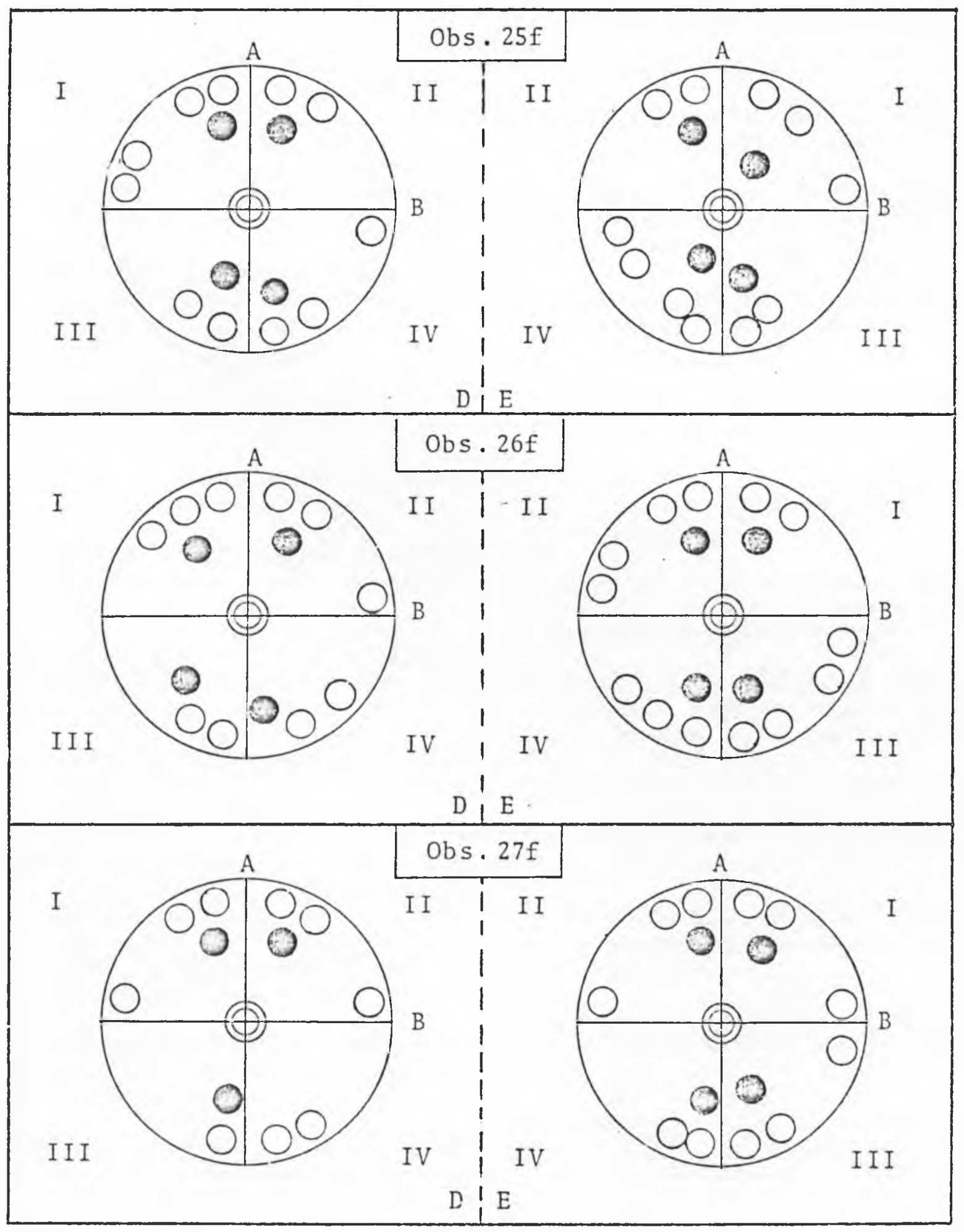

Rev.Fac.Med.vet.Zootec.Univ.S.Paulo, 22(2): 77.95, 1985 


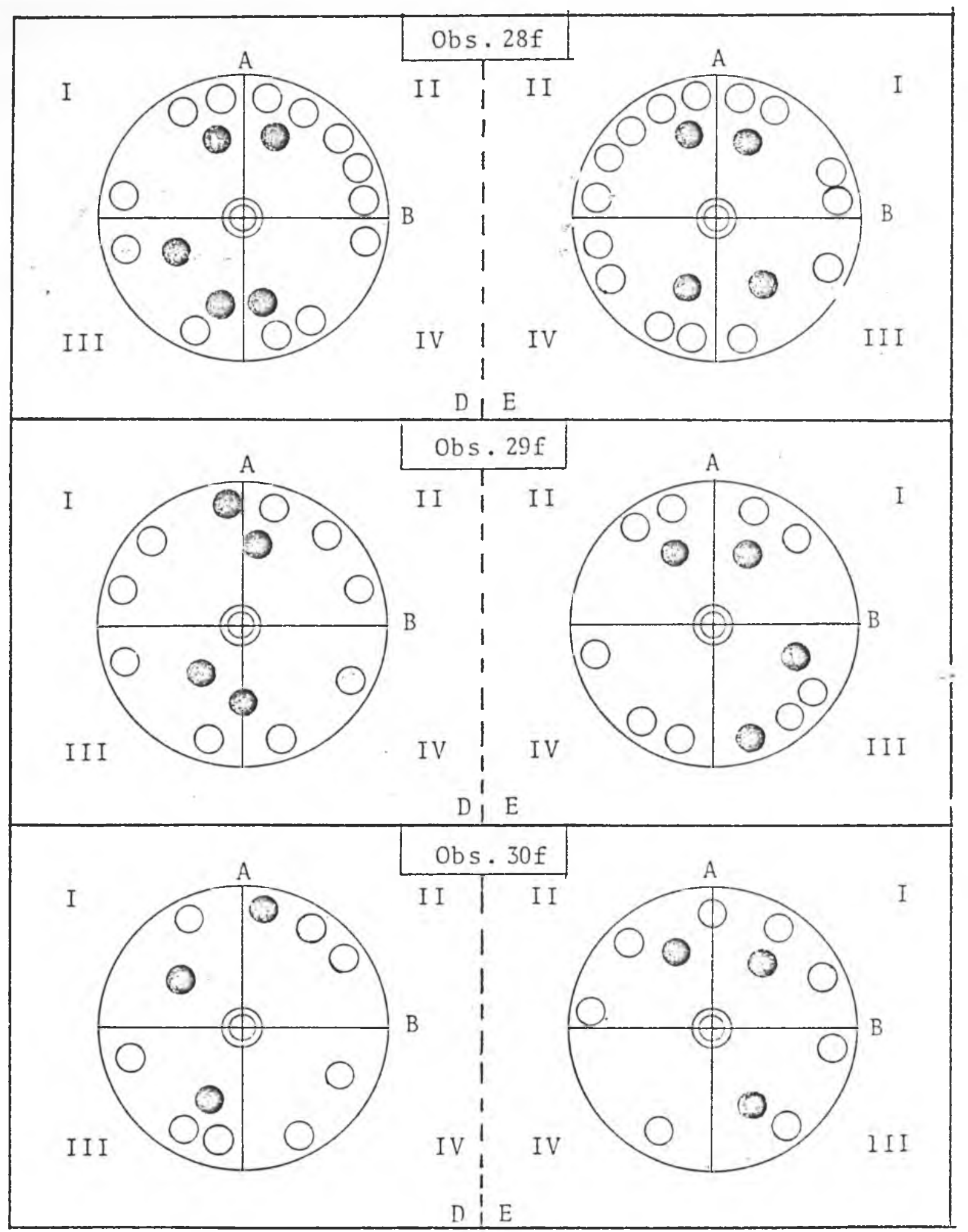




\section{REFERENCLAS BIBLIOGRÄFICAS}

1- ARNAUTOVIC, I. The distribution of the renal artery in the kidney of the dog. Brit. vet. J., 115:446-8, 1959.

2- BOSSI, V.; CARADONNA, G.B.; SPAMPANI, G. V.; ZIMMERL, U. Trattato di anatomia veterinária. Milano, Francesco Vallardi, s.d. v.2, p.207.

3- BRADLEY, O.Z. Topographical anatomy of the dog. 5.ed. Edinburgh, Oliver and Boyd, 1948. p.89-90.

4- BRUNI, A.C. \& ZIMMERL, U. Anatomia degli animali domestici. Milano, Francesco Vallardi, 1947. p.153.

5- COLLIN, B. Les vaisseaux sanguins du rein chez les chien. Ann. Méd, vét., 116:631-46, 1972.

6- DOBBERSTEIN, J. \& HOFFMANN, G. Lehrbuch der vergleichenden Anatomie der Haustiere. Leipzig, S. Hirzel, 1963. v.2, p.136.

7- ELLENBERGER, W. \& BAUM, H. Anatomie descriptive et topographique du chien. Paris, C. Renwald, 1894. p.416-7.

8- EVANS, H.E. \& CHRISTENSEN, G.C. Miller's anatomy of the dog. 2.ed. Philadelphia, Saunders, 1979. p.550-1.

9- FERRAZ, J.B.S.; PEREIRA, D.A.; VARGAS, R.Q.; CARVALHO, I.A. Contribuição ao estudo dos elementos vasculares arteriais e venosos do hilo renal em cres. In: CONGRESSO BRASILEIRO DE MEDICINA VETERINÁRIA, 14., São Paulo, 1974. Anais. p.170.

10- FULLER, P.M. \& HUELKE, D.F. Kidney vascular supply in the rat, cat and dog. Acta anat., Basel, 84:516-22, 1973.

11- GONZALES Y GARCIA, J. \& GONZALEZ ALVAREZ, R. Anatomia comparada de los animales domésticos. 7.ed. Zaragoza, La
Académica, 1961. p.631.

12- KOCH, T. Lehrbuch der Veterinär - Anatomie. s.L., Gustav Fischer, 1963. p.234-5.

13- LESBRE, F.X. Précis d'anatomie comparée des animaux domestiques. Paris, J.B. Baillière, 1923. v.2, p. 78,80 .

14- MARTIN, P. Lehrbuch der Anatomie der Haustiere. Stuttgart, Schickhardt \& Ebner, 1904. v.2, p.861.

15- MILLER, M.E. Guide to the dissection of the dog. 3.ed. Ithaca, 1952. p. 220 .

16- MONGIARDINO, C. Trattato di anatomia topografica dei mammiferi domestici. Torino, Luigi Delgrosso, 1903. p.192.

17- MONTANÉ, L.; BOURDELlE, E.; BRESSOU, C. Anatomie régionale des animaux domestiques. Paris, J.B. Baillière, 1953. p.374.

18- NICKEL, R.; SCHUMMER, A.; SEIFERLE, E.; SACK, W.O. The viscera of the domestic mammals. Berlin, Paul Parey, 1973. p.287.

19- REIS, R.H. \& TEPE, P. Variations in the pattern of renal vessels and their relation to the type of posterior vena cava in the dog (Canis familiaris). Amer.J.Anat., 99:1-15, 1956.

20- SCHWARZE, E. \& SCHRŐDER, L. Compêndio de anatomia veterinária. Zaragoza, Acribia, 1970. v.2, p.234-5.

21 - SISSON, S. \& GROSSMAN, J.D. Anatomia de los animales domesticos. 4.ed. Barcelona, Salvat, 1959. p.658.

22- ZIMMERL, U.; BRUNI, A.C.; CARADONNA, G.B.; MANNU, A.; PREZIUSO, L. Trattato di antonisa veterinaria. Mulano, Francesco Vallardi, 1930. v.3, p.15, 18.

Recebido para publicação em: 01/04/85 Aprovado para publicaçâo em: 28/06/85

Rev.Fac.Med.vet.Zootec.Univ.S.Paulo, 22(2): 77-95, 1985 